\title{
An approach to diagnostic dilemma in thyroid cytopathology
}

\author{
Pant $\mathrm{R}^{1}$ \\ ${ }^{I}$ Department of Pathology, Shree Birendra Hospital, Kathmandu, Nepal
}

Dear editor;

The article in the last issue of the Journal of Pathology of Nepal entitled "Role of fine needle aspiration cytology in the diagnosis of thyroid lesions" (Journal of Pathology of Nepal (2012;2:186-8) struck a chord with me because I believe almost all pathologists have had a sour experience with cytological evaluation of thyroid lesions. The authors too record a false negative case where a cytological report of adenomatous goiter was discrepant with the final histopathological diagnosis of follicular carcinoma. I congratulate the authors for not having come across, in their correlative study of 20 patients, a disappointing situation when a papillary carcinoma is misdiagnosed as a colloid goiter on fine needle aspiration cytology (FNAC). Most of us must have been dismayed when a colloid goiter we had reported on cytology turns out to be papillary carcinoma on histology and we are reminded by the clinician about our incapacity to differentiate between benign and malignant lesions which has resulted on the patient being subjected to a second difficult operation which could have easily been managed by an initial near-total thyroidectomy had we reported it correctly. Cystic change is known to be present in about $25 \%$ of papillary carcinoma and if the cystic area is sampled, scattered cyst macrophages are inevitable in a colloidrich background which prompts an impression of cystic change in colloid goiter.

I feel the only way to avoid this embarrassing situation is to incorporate both the clinical information and the ultrasonographic features along with cytopathological features in the final report as shown in Table 1. Whenever a diagnostic dilemma necessitates a repeat FNAC, a structured tabulated reporting format on a single paper allows the clinician to tick the presence or absence of pertinent clinical features like history of neck irradiation and thyroid cancer in family, firmness of nodule, rapid growth, fixation to adjacent structures, vocal cord paralysis and regional lymphadenopathy. While performing FNAC to sample the solid area of the solidocystic lesion, the radiologist records important ultrasonographical features like the size of the lesion and ticks the relevant specified feature regarding echogenicity, composition, microcalcification, halo, margins, internal blood flow, lymph nodes. He also mentions the specimen submitted. The pathologist analyzes the smears with the help of clinical and ultrasonographical information and encircles the appropriate category according to the Bethesda system with implied risk of malignancy and recommended clinical management. Similar reporting format can also be utilized to evaluate colloid-poor proliferative thyroid lesions that cannot be categorized on initial FNAC. A nondiagnostic or inconclusive repeat FNAC report should be followed by a surgical procedure for histopathological evaluation. 
Table 1: Evaluation of nodular thyroid lesion

Clinical Features

\begin{tabular}{|c|c|c|}
\hline Features & Present & Absent \\
\hline \multicolumn{3}{|l|}{$\mathrm{H} / \mathrm{O}$ Neck irradiation } \\
\hline \multicolumn{3}{|l|}{$\mathrm{H} / \mathrm{O}$ Thyroid cancer in family } \\
\hline \multicolumn{3}{|l|}{ Firmness of nodule } \\
\hline \multicolumn{3}{|l|}{ Rapid growth } \\
\hline \multicolumn{3}{|l|}{ Fixation to adjacent structures } \\
\hline \multicolumn{3}{|l|}{ Vocal cord paralysis } \\
\hline Regional lymphadenopathy & & \\
\hline
\end{tabular}

\section{Ultrasongraphic Features}

\begin{tabular}{ll}
\hline Features & \multicolumn{1}{c}{ Description } \\
\hline Size & \\
\hline Echogenicity & Hypoechoeic / Hyperechoeic \\
\hline Composition & Solid / Predominantly solid / Mixed solidocystic / Predominantly cystic / Cystic \\
Microcalcification & Present / Absent \\
\hline Halo & Present / Absent \\
Margins & Regular / Irregular \\
\hline Internal blood flow & Present / Absent \\
\hline Lymph nodes & Heterogenous echotexture / Calcification / Cystic areas / Round / Mass effect \\
\hline Specimen submitted & \\
\hline
\end{tabular}

\section{Cytopathologic Impression}

\begin{tabular}{lcl}
\hline Diagnostic category & Implied risk of malignancy (\%) & Recommended clinical management \\
\hline Nondiagnostic or Unsatisfactory & $1-4$ & Repeat FNA with ultrasound guidance \\
Benign & $0-3$ & Clinical follow-up \\
$\begin{array}{l}\text { Atypia of undetermined significance or Follicular lesion of } \\
\text { undetermined significance }\end{array}$ & $\sim 5-15$ & Repeat FNA \\
Follicular neoplasm or Suspicious for a follicular neoplasm & $15-30$ & Surgical lobectomy \\
Suspicious for malignancy & $60-75$ & Near-total thyroidectomy or surgical \\
lobectomy & & Near-total thyroidectomy \\
\hline Malignant & $97-99$ &
\end{tabular}

In the end, it is imperative for clinicians, radiologists and pathologists to understand and accept with humble dignity that even with exhaustive exercise, some thyroid lesions, like some lesions in any other part of the body, defy categorization on FNAC and must be subjected to thorough histopathological evaluation for proper management of the patient.

\section{Correspondence:}

Dr Rajesh Panth, MBBS, MD

Consultant Pathologist

Department of Pathology

Shree Birendra Hospital

Kathmandu, Nepal

E-mail: rajeshreeta1981@yahoo.com 